for the trifluoride of phosphorus and chlorine are found to react in equal volumes, and the combination is attended by a contraction of one-half. The new gas may therefore be considered as phosphorus chlorofluoride, $\mathrm{PCl}_{2} \mathrm{~F}_{3}$, the chlorine derivative of phosphoryl and thiophosphoryl fluoride, $\mathrm{POF}_{3}$ and $\mathrm{PiF}_{3}$.

The most convenient mode of preparation is described as follows. Two flasks of equal capacity (about 500 c.c.) are taken, and filled respectively with phosphorus trifluoride and chlorine. They are connected together by a bent tube passing through the stoppers, and the flask containing the phosphorus trifluoride is further connected with a reservoir of mercury in such a manner that a gentle pressure may be placed upon the trifluoride, so as to gradually displace it over into the chlorine. The two flasks being of equal capacity, it is evident that, when the whole of the trifluoride has thus been transferred, the reaction is $\mathrm{com}$ pleted, the green colour of the contents of the other flask disappears, and the remaining gas is almost pure chlorofluoride. After allowing to stand a few days in contact with the mercury, in order to remove the last traces of chlorine, the gas is ready for examination.

Phosphorus chlorofuoride is a colourless incombustible gas, possessing a powerfully irritating odour. It is instantly absorbed aid decomposed by water and by solutions of alkaline or alkaline eartby hydrates. A determination of its vapourdensity gave the number $54^{\circ}$, sufficiently near the theoretical density of a substance $\mathrm{PCl}_{2} \mathrm{~F}_{3}\left(5^{\circ} 46\right)$. It is comparatively easily liquefied, a temperature of $-8^{\circ} \mathrm{C}$. being sufficient at ordinary pressures. It is dissociated at a temperature of $250^{\circ} \mathrm{C}$. into gaseous pentafluoride and solid pentachloride of phosphorus. The induction spark effects the same decomposition.

Sulphur reacts with phosphorus chlorofluoride in a most in teresting manner. The reaction commences about the meltingpoint of sulphur, I I $5^{\circ} \mathrm{C}$, and the products are chloride of sulphur and gaseous thiophosphoryl fluoride, $\mathrm{PSF}_{3}$. And here a most emphatic protest must be made against the manner in which many French chemists persistently ignore the work of the chemists of other countries. Thiophosphoryl fluoride, $\mathrm{PSF}_{3}$, was discovered and prepared three years ago in the Research Laboratory of the Royal College of Science, South Kensington, by Prof. Thorpe and Mr. J. W. Rodger; and a detailed account, illustrated by experiments, of the mode of preparation and properties of this remarkable gas, was laid before the Chemical Society and published in their Journal. ${ }^{1}$ And yet, in the memoir just presented by M. Moissan, we find this compound, a description of which long ago found its way into the abstracts or referate of most foreign journals, described as " un nouveau composé gaseux." Indeed, a considerable amount of unnecessary trouble appears to have been taken in order to ascertain the composition of this "new gas"-trouble which, as the compound is so readily recognizable by its extraordinary properties, might have been saved, if the author had taken the pains to look up the literature of the subject. It is high time that French chemists should look to their "prestige" in this respect, for, unfortunately, the present is by no means the only case which has within the last few months come before the notice of the writer of this note, in which compounds fully described and worked out by English chemists have been rediscovered and described as new by French authors.

When phosphorus chlorofluoride is passed over free phosphorus heated to $\mathrm{I}^{\circ} \mathrm{O}^{\circ}$, it is decomposed with formation of phosphorus trifluoride, which passes away as gas, and phosphorus trichloride, which condenses in liquid drops. Metallic sodium, when slightly heated, appears to absorb the chlorofluoride entirely, while magnesium, aluminium, iron, nickel, lead, and tin, when heated to about $180^{\circ}$, attack the gas with formation of anhydrous chlorides and liberation of phosphorus trifluoride. Mercury attacks it very slowly at the ordinary temperature, but very rapidly at $180^{\circ}$, with formation likewise of a chloride of the metal and gaseous trifluoride of phosphorus. Hence, when purifying the gas from the last traces of chlorine, the mercury should not be agitated, but allowed to remain at rest, as agitation brings about a perceptible amount of decomposition.

Water reacts in two stages with phosphorus chlorofluoride. When a little aqueous vapour is admitted into the vessel inclosing the gas, phosphoryl fluoride and hydrochloric acid are formed in accordance with the equation-

$$
\mathrm{PCl}_{2} \mathrm{~F}_{3}+\mathrm{H}_{2} \mathrm{O}=\mathrm{POF}_{3}+{ }_{2} \mathrm{HCl} \text {. }
$$

When passed into water, however, the gas is completely Journ. Chem. Soc. Trans, 1889, vol. lv. p. 305. decomposed into phosphoric, hydrochloric, and hydrofluoric acids-

$$
\mathrm{PCl}_{2} \mathrm{~F}_{3}+{ }_{4} \mathrm{H}_{2} \mathrm{O}=\mathrm{H}_{3} \mathrm{PO}_{4}+2 \mathrm{HCl}+3 \mathrm{HF} \text {. }
$$

Ammonia gas reacts at the ordinary temperature with production of a white solid compound, readily soluble in water, which appears to be fluophosphamide, $\mathrm{PF}_{3}\left(\mathrm{NH}_{2}\right)_{2}$.

$$
\mathrm{PCl}_{2} \mathrm{~F}_{3}+4 \mathrm{NH}_{3}=\mathrm{PF}_{3}\left(\mathrm{NH}_{2}\right)_{2}+2 \mathrm{NH}_{4} \mathrm{Cl} \text {. }
$$

Phosphorus chlorofluoride is absorbed by absolute alcohol with production of a compound possessing a penetrating odour, and which burns with a bright flime bordered with green, and leaves a white residue of phosphoric acid. The nature of this compound has not yet been fully ascertained.

These properties of phosphorus chlorofluoride indicate that the gas is much less stable than the pentafluoride, and that the two atoms of chlorine possess a mobility which renders their removal a matter of considerable ease. A. E. Tutron.

\section{PROF. MENDELEEFF ON THE VARIATION OF} THE DENSITY OF WATER AT DIFFERENT TEMPERA TURES.

THE last number of the Journal of the Russian Physical and Chemical Society (I89I, No. 5) contains an important paper, by Prof. Mendeleeff, upon the variation of the density of water at different temperatures. In a work, published in 1884 and translated into English in the Journal of the Chemical Society, the Russian Professor proposed the formula $\mathrm{S}_{t}=\mathrm{S}_{o}(\mathbf{I}-k t)$ as a first approximation to a mode of expressing the expansion of liquids at a certain distance from the temperatures at which they change their state, and within the limits of accuracy attained in the present determinations. But he remarked that the expansion of water would require a separate formula, and he now proposes the formula

$$
\mathrm{S}_{t}=\mathrm{r}-\frac{(t-4)^{2}}{(\mathrm{~A}+t)(\mathrm{B}-t) \mathrm{C}},
$$

which embodies, with sufficient accuracy, all that is yet known about changes in the density of water $\left(\mathrm{S}_{t}\right)$ within the limits of from $-10^{\circ}$ to $+200^{\circ}$. For alls liquids save water, the increase of density with the increase of temperature, that is, the derived $\frac{d s}{d t}$, varies but little; it but slightly increases or slightly decreases with considerable changes of temperature; while for water, $\frac{d s}{d t}$ not only changes its sign at $+4^{\circ}$, but very rapidly varies even at temperatures remote from zero, and even superior to $100^{\circ}$. After confirming the above by a few examples, Prof. Mendeleeff indicates the faint relations between his new formula for water and the general law of the expansion of liquids, by explaining the way in which he arrived at his new formula. He points out, moreover, that under the present state of the determinations of the density of water at various temperatures, it would be impossible to find exact figures for the constants $\mathrm{A}, \mathrm{B}$, and $\mathrm{C}$, in the above formula, and that provisionally, and especially for temperatures between $0^{\circ}$ and $40^{\circ}$, they may be taken as follows :- $\mathrm{A}=94^{\circ} \mathrm{I}$, $\mathrm{B}=703^{\circ} \mathrm{I}^{\circ}$, and $\mathrm{C}=1.90$.

Prof. Mendeleeff then goes on briefly to analyze the various corrections which ought to be taken into account in the determinations of the density of water; namely, the influence of pressure, the expansion of solids, and the measurements of temperature. All these being taken into account, it appears that the errors of the best determinations of densities attain several units in the fifth decimals, even at common temperatures. After many unsuccessful attempts at improving the current figures of densities by introducing into them several corrections, Prof. Mendeleeff abandoned the idea, and he now gives the authentic figures, as they were published by the investigators themselves, simply expressing all determinations in volumes for the sake of facilitating comparison. The figures published by Hallström (1823), Muncke (1828), Stampfer (I831), Despretz (I837), Pierre (I847), Kopp (1847), Pliicker and Geissler (1852), Hagen (1855), Henrici (1864), Jolly (1864), Matthissen (1865), Weidner (1866), and Rosetti (1869), are thus given in a first table. The figures, as they were corrected by biot in $18 \mathrm{II}$, Hallström in 1835, Miller in 1856 , Rosetti in 1871 , Volkmann in $188 \mathrm{r}$, Mendeleeff in 1884 , and Makaroff in I89I, are given in a second table.

The averages of the volumes of water derived from the original

NO. I I 36, vOL. 44] 
figures (Table I.), at temperatures from $-5^{\circ}$ to $+100^{\circ}$, taking the volume at $4^{\circ}$ equal to $1,000,000$, and the pressure being equal to one atmosphere, appear as follows in the sec ond column $\left(\mathrm{V}_{t}\right)$ of the subjoined table. They are followed, in the third column, by the volumes as calculated from Prof. Mendeleeff's new formula :-

\begin{tabular}{|c|c|c|c|c|c|}
\hline t. & $v_{t .}$ & $\begin{array}{l}\qquad V_{t}=\frac{\mathrm{I}}{\mathrm{S}_{t}} \\
\text { calculated from } \\
\text { the furmula. }\end{array}$ & $\begin{array}{c}\frac{d V}{d t} \\
\text { for } x^{0}\end{array}$ & $\begin{array}{c}\frac{d \mathrm{~V}}{d p} \\
\text { for I atmo } \\
\text { sphere. }\end{array}$ & $\begin{array}{c}\text { Possible } \\
\text { errors of the } \\
\text { present deter } \\
\text { minations. }\end{array}$ \\
\hline$-\stackrel{0}{-5}$ & I 000662 & I 000676 & -1 & -52 & 干 29 \\
\hline 0 & I 000 & 127 & -65 & -5 & $\mp 12$ \\
\hline+5 & I 000008 & I 000008 & +15 & -48 & \pm 3 \\
\hline 10 & I 000263 & 262 & +8 & -47 & \pm 15 \\
\hline 15 & I 000847 & 849 & $+I_{4}$ & -46 & \pm 26 \\
\hline 20 & I OOI 733 & $73 \mathrm{I}$ & $+20_{4}$ & -45 & \pm 35 \\
\hline 25 & $100287 \mathrm{I}$ & 880 & +2 & -44 & \pm 43 \\
\hline 30 & I 004248 & 276 & & -8 & \pm 49 \\
\hline 40 & 1007700 & 725 & +3 & $-4 I$ & \pm 59 \\
\hline 50 & I OII 9 & & & -40 & \pm 67 \\
\hline 60 & I 016 & 926 & +5 & -39 & \pm 75 \\
\hline 70 & 1022 & & & -4 & \pm 85 \\
\hline 80 & 10288 & & & -4 & t 9 \\
\hline 90 & 10357 & I 035692 & +719 & -42 & \pm 118 \\
\hline 100 & I 043180 & I 043 I94 & +781 & -44 & $\pm \mathrm{I} 45$ \\
\hline
\end{tabular}

Finally, a third table is given, being the result of the calculation made by taking

$$
\begin{gathered}
\mathrm{S}=\mathbf{I}-\frac{(t-4)^{2}}{\mathrm{I} 000 \phi(t)}, \\
\phi(t)=\mathbf{1} 28.78+\mathbf{I} \cdot \mathbf{I} 58 t-0.0019 t^{2},
\end{gathered}
$$

and

$$
1000 \phi(t)=\mathbf{I} \cdot 90(94 \cdot 10+t)(703 \cdot 5 \mathbf{I}-t),
$$

and extending the calculation to $+200^{\circ}$ and $-10^{\circ}$. The most important values of $\frac{d s}{d t}$ are given in the fourth column of the subjoined table; so, also, the approximate values of $\frac{d s}{d p}$, which

\begin{tabular}{|c|c|c|c|c|c|c|}
\hline$t^{\nu} \mathrm{C}$ & $\begin{array}{l}\text { Calculated } \\
\text { densitie;, } \mathrm{S}_{\ell}\end{array}$ & 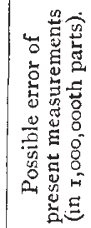 & 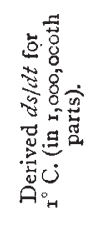 & 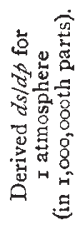 & $\begin{array}{c}\text { Numerical } \\
\text { values of } \\
\phi(t) .\end{array}$ & $\begin{array}{c}\text { Calculated } \\
\mathbf{V}_{t^{\prime}}\end{array}$ \\
\hline-10 & $0.99828 \mathbf{I}$ & $\mp 49$ & +264 & +54 & I $44^{\circ}$ OI & 1.001722 \\
\hline 5 & 999325 & $\mp 29$ & $\begin{array}{r}157 \\
+\quad 15\end{array}$ & 52 & I 19.94 & 000676 \\
\hline 0 & 999873 & $\mp 12$ & +65 & 50 & 12578 & 000127 \\
\hline+5 & 999992 & \pm 3 & $-\quad 15$ & 48 & $\times 31 \cdot 52$ & 000008 \\
\hline 10 & 999738 & \pm 15 & -85 & 47 & $137^{\circ} 17$ & 000262 \\
\hline 15 & 999 I 52 & \pm 26 & -148 & 46 & 142.72 & 000849 \\
\hline 20 & 998272 & \pm 35 & -203 & 45 & $148 \cdot 18$ & OOI $73 \mathrm{I}$ \\
\hline 25 & 997 I 28 & \pm 43 & -254 & 44 & $\times 53.54$ & 002880 \\
\hline 30 & 995743 & \pm 49 & - 299 & 43 & $158.8 \mathrm{r}$ & 004276 \\
\hline 40 & 992334 & \pm 53 & -380 & $+4 I$ & 169.06 & I 007725 \\
\hline 50 & 988 I 74 & 65 & $-45^{\circ}$ & 40 & $178 \cdot 93$ & or I 967 \\
\hline 60 & 983356 & 72 & -512 & 39 & 188.42 & 016926 \\
\hline 70 & 977948 & 80 & -569 & 39 & $197^{\circ} 53$ & 022549 \\
\hline 80 & $97 \times 996$ & 92 & $-62 I$ & 40 & $206 \cdot 26$ & 028811 \\
\hline 90 & 965.537 & 109 & -670 & 41 & 214.61 & 035692 \\
\hline 100 & 958595 & 133 & -718 & $4^{2}$ & $222 \cdot 5^{8}$ & 043194 \\
\hline 120 & $9433 \mathrm{I} 4$ & \pm 600 & -810 & +43 & $237 \cdot 38$ & I 060093 \\
\hline 140 & $9262 \mathrm{II}$ & 650 & -901 & 48 & 250.66 & 079667 \\
\hline 160 & 907263. & 700 & -995 & 55 & 26242 & 102216 \\
\hline 180 & 886393 & $75^{\circ}$ & - - I093 & 64 & $272 \cdot 66$ & 128167 \\
\hline 200 & 863473 & 800 & -1200 & 73 & $28 \mathrm{I} \cdot 38$ & 158 II 4 \\
\hline
\end{tabular}
are "but a first rough approximation," to show the importance of pressure in the determinations of volumes of water :-

NO. I I 36 , VOL. 44$]$
In conclusion, Prof. Mendeleeff repeats that he proposes as soon as possible to make anew the determination; of the densities of water, because the former determinations were made on assumptions (permanency of the coefficient of the expansion of glass and mercury, and no notice being taken of pres:ure) which can no longer be maintained. If new measurements confirm the formula, or lead to a more correct one, we shall be better able to understand the laws of the expansion of all liquids, and therefore of gases as well. "In the case of water," he says, "we have begun to understand more clearly the influence of heat upon densities and volumes, and I believe that with the help of water we may expect some further progress in the study of the influence of heating upon matter."

\section{UNIVERSITY AND EDUCATIONAL INTELLIGENCE.}

OXForD. - The examiners in the Final Classical Schools issued the Class List on Wednesday week, completing the results of the examinations held in Trinity Term.

The summer meeting of Extension students commenced on Friday last, when Mr. Frederic Harrison, M.A. Wadbam College, delivered the inaugural lecture. The popularity of the movement is proved not only by the continual increase in the number of students who avail themselves of the advantages offered hy this system of education, but by the interest which foreign Governments are taking in the development of the plan. The French Government have sent two special commissioners to report on the prospects and condition of the University Extension movement, and a large number of the representatives of the American University Exiensionists are now in Oxford

The number of students attending the varions lectures is greater than on any previous occasion, more than xIOO having subscribed, while last year the number did not greatly exceed 900. A more rapid growth and a still greater measure of success attending the work may tre anticipated from the fact that various County Councils, finding themselves in possession of funds arising from the operation of the Local Taxation Act, and which they propose to devote to the purposes of technical instruction, are availing themselves of the machinery of the University Extension system to accomplish this desirable end.

\section{SCIENTIFIC SERIAISS.}

IN the Botanical Gazette for June, Mr. T. Holm coutributes a study of some anatomical characters of North American grasses. In a paper entitled "On the Relation between Insects and the Forms and Characters of Flowers," Mr. T. Meehan epitomizes his views on fertilization opposed to the current theory, viz. that the part played by insects in the fertilization of flowers has been greatly exaggerated; that flowers do not abhor crosspollen; and that all annuals can self-fertilize when crossfertilization fails, annuals in almost all cases having every flower fertile.

THE most important paper in the Journal of Botany for July is the commencement of a detailed account of the Algr of the Clyde sea-area, by Mr. George Murray, Secretary to the Committee for the Exploration of the Marine Flora of the West of Scotland. This is prefaced by an account of the physical features of the Clyde sea-area, by Dr. John Murray. Following this is the commencement of a hand-list of the Algæ, by Mr. E. A. L. Batters. The Rev. H. G. Jameson concludes his key to the genera and species of British mosses, which it is hoped may be published in a separate form; and Mr. George Murray sinks Hooker's genus of sea-weeds Cladothele in Stictyosiphon.

\section{SOCIETIES AND ACADEMIES. PARIS.}

Academy of Sciences, July $27 .-\mathrm{M}$. Duchartre in the chair. - Proofs that Asia and America have been connected in recent times, by M. Emile Blanchard. In this paper the author points out certain species of Asiatic fauna and flora which are found in North America, as, in the preceding one, he indicated the representatives of European fauna and flora which occur in the same continent. Without making an extensive enumeration of the 